\title{
Examining the Effect of Reviewer Socioeconomic Status Disclosure on Customers' Purchase Intention
}

\author{
Yuming Liu, Xidian University, Xi'an, China \\ Rong Du, Xidian University, Xi'an, China
}

\begin{abstract}
Image reviews can directly indicate socioeconomic status (SES) of reviewers, which is completely different from text reviews. However, image reviews are under the way to be deeply explored the effect of reviewers' SES disclosures on customer purchase intention. This research uses experimental method to examine social status effect of reviewers in different consumption settings and the underlying mechanism. The findings demonstrate that SES disclosure of reviewers has a significant influence on customers' purchase intentions, indicating that participants have higher purchase intention when they perceive that the products are recommended by high SES reviewers than by low SES reviewers. However, the social status effect occurs when the product is consumed in public but does not occur when the product is consumed in private. This research also finds that participants with high selfpresentation concerns would be significantly influenced by reviewers' SES when a product is consumed in public, but participants with low self-presentation concern would not be influenced.
\end{abstract}

\section{KEYWORDS}

Online Review, Product Consumption Setting, Self-Presentation Concern, Socioeconomic Status (SES)

\section{INTRODUCTION}

Online reviews have become an important product information source for consumers as they make final purchase decision; therefore, online reviews are considered to be an indispensable tool for online vendors to promote their products (Pan \& Zhang, 2011; Khare et al., 2011). For the benefits of buyers and vendors, most shopping websites across the globe have been constantly developing their review systems to improve consumers' shopping experiences (Srinivasan et al., 2002), to help them make better purchase decisions, and to increase vendors' sales (Chen et al., 2011).

Currently, image reviews, a form of online reviews, are becoming more common in review systems for most leading shopping websites, such as Amazon.com and Taobao.com. By using customer image reviews, online vendors want to attract more potential customers and improve their own profitability. Image reviews present product pictures that customers take personally, even customers' selfies with the products. Image reviews often disclose actual customers' social status information unintentionally. In other words, online vendors just intend to attract more customers via trustworthy image reviews, 
but the reviews often present unintentional social status cues of reviewers at the same time. Online vendors have to consider whether the social status disclosures of reviewers would positively impact customers' purchase intention.

In practice, most text-based online reviews do not disclose any social status information from reviewers, especially from anonymous ones (Forman et al., 2008). On the other hand, most imagebased online reviews disclose reviewers' social status cues more or less when actual customers present product images within reviews. However, previous research only targeted sources disclosure based on verbal descriptive information in text reviews, such as reviewers' real name, location (Forman et al.,2008), low versus high occupation status (security guard vs. architect) (Shalev \& Morwitz, 2012), and demographic similarity (gender, age, occupation and education). Although image-based online reviews have started to interest some scholars, little is known about the effect of social status disclosure of reviewers on image-based online reviews.

Past research has demonstrated that prior customers' socioeconomic status (SES) could influence purchase intention of potential customers (Shalev \& Morwitz, 2012). Extending this perspective to image-based online reviews, the current research examines the effect of reviewers' SES on the purchase intentions of potential customers based on image reviews. Utilizing product consumption theory, the authors further argue the moderation effect of different product consumed settings on social status effect. The authors also demonstrate the underlying mechanism of social status effect. Moreover, the authors discuss an effective way to improve SES positive impact. To test the hypotheses, the authors use experimental method. The authors' work deepens the understanding of reviewers' social status effect in theory. In practice, the findings in this research could benefit online vendors by identifying more persuasive image reviews. The research results also provide clear instructions about how to improve customers' purchase intention by technologically deal with image reviews.

\section{THEORETICAL BACKGROUND}

\section{Social Status Effect of Online Reviews}

An image-based online review is an important presentation format to provide product information for potential customers. Social status disclosure of reviewers is presented in a nonverbal format in image reviews. Visual cues are more believable than verbal descriptive information, and they also make information more intuitive to review readers. Specifically, reviewers' SES cues could be disclosed directly from product background in image reviews. Comparing the following two image reviews of clothing, the text content is identical, but the SES of the reviewer is high or low individually (see Figure 1). Potential customers would see clothing photographed with different backgrounds embedded in image online reviews. Which image reviews will be considered more persuasive to potential customers?

Socioeconomic status is an important variable influencing customers' attitudes and behaviors in marketing literatures. Customers with higher SES have more significant influence than average customers (Boster et al., 2009), and they are more persuasive than others as well (Strodtbeck et al., 1957). Customers with lower SES might decrease persuasive effect of their suggestion (Solomon \& Englis, 1996) and make potential customers less interested in buying products they recommend (Shalev \& Morwitz, 2012). The authors define this influence as a "social status effect" in this research. Online social status effect can be more significant than offline social status effect. It is difficult for potential customers to know about social status cues of prior customers when they buy products in offline shops. Most of them are strangers and have not seen each other. Very few cues could stimulate social status effect. By contrast, online image reviews provide an opportunity for potential customers to observe social cues of actual buyers. Social status effect would be generated directly.

However, social status effect is double-edged. Online vendors probably could not achieve their desired goals based on image online reviews. It could even backfire. It is very important for online 


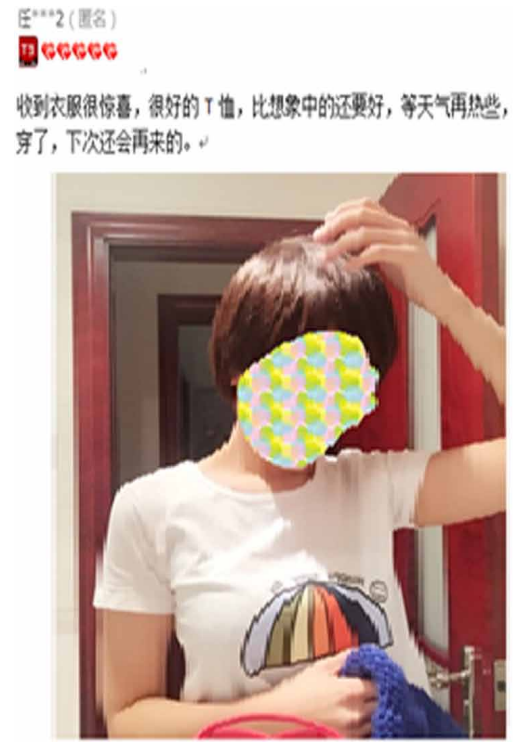

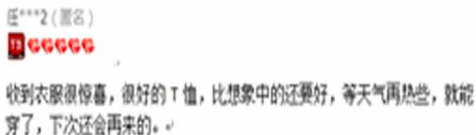

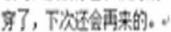

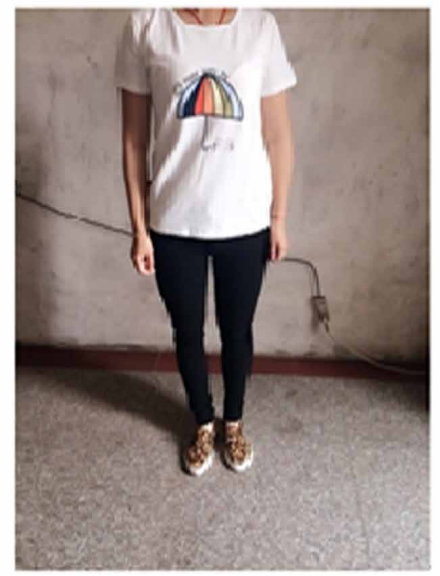

vendors to understand how reviewers' SES information embedded in image reviews impacts potential customers' product attitudes.

\section{Online Reviews and Purchase Intention}

Online reviews present important information about actual customers' product evaluation to potential customers. Moreover, online reviews have a significant impact on customer purchase intention. However, past research mainly focuses on the influence of text content attributes of online reviews, such as review valance and argument quality (Zhang et al., 2014; Ketron, 2017). Some studies have started to explore the effect of reviewers on customer purchase intention, such as perceived source trustworthiness (López \&Sicilia, 2014; Banerjee et al., 2017).

Furthermore, past research also focuses on reviewer identity-related information (Formanet al., 2008; Shalev \& Morwitz, 2012). For example, Shalev and Morwitz (2012) demonstrated the influence of the low-status influencer on customer purchase intention. This research focused on reviewers' self-descriptions about their occupation (security guard vs. architect) in text-based online reviews. However, few actual customers would like to describe their own occupation information in online reviews in practice. Similarly, reviewers' real names or locations in other research (Forman et al., 2008) would not usually be provided by actual reviewers on current shopping websites, especially in China. Recently, some researchers have begun to focus on the influence of reviewer profile images on perceived helpfulness (Karimi \&Wang, 2017).

However, the authors consider that potential customers probably prefer to read image reviews than profile images. To deepen the understanding about interpersonal influence from customer image reviews, the authors examine the effect of social status information from image reviews on customer purchase intention, and the authors explore the mechanism of the effect of reviewers' SES on potential customers' purchase intention.

\section{Product Consumption and Social Status Effect}

Product-social behavior relationships have received much attention in the social and marketing sciences. Products are no longer consumed for their functional values in use but for symbolic values to satisfy the users' social wants (Levy, 1959; Bhat \& Reddy, 1998; Prónay \& Hetesi, 2016; Park et 
al., 1986). For example, appearance-related products, such as clothing, are no longer a mere means of warmth but are viewed as symbolic products of social status for individuals (Belk et al., 1982; Solomon, 1983). Thus, product consumption is one way for users to express their social self-image (Schenk\& Holman, 1979), social identification (Banister \& Hogg, 2004) and social status (Ekinci et al., 2013). Customers use products to assist themselves in the creation, confirmation and communication of their own identity (Belk et al., 1982; Bhat\& Reddy, 1998).

Product consumption is symbolic for customers (Holt, 1998). However, customer-product interactions do not provide the whole story. Hirschman (1981) considered that a sender and receiver were required for a symbol (Hirschman, 1981). Thus, symbolic interactionism explains the interrelationships among customers, products and audiences (Hogg et al., 2009). The customerproduct relationship is essentially a bidirectional interactive effect. People (audiences) evaluate others (customers) largely based on their own possessions (products) (Solomon, 1983). However, the link direction between customers and products is sometimes reversed. Potential customers (audiences) also evaluate products based on their users' status (prior customers) (Sengupta et al., 2002; Ekinci et al., 2013).

When product users convey socioeconomic status impressions to a future customer, social status effects take place. Shalev and Morwitz (2012) suggested that "consumers do not aspire to be members of a low-status group and would not normally accept influence from actual members of that group." Thus, low-status sources usually exert negative influences on potential customers' attitudes about products. Potential customers reject the products consumed by low-status sources when they wish to dissociate from them (Shalev \&Morwitz, 2012). High status customers use product consumption to differentiate themselves from low status ones (Veblen, 1994). Moreover, customers tend to positively evaluate opinions provided by customers with high socioeconomic status (Corey, 1971).

In previous research, source cues in text-based online reviews are based on descriptive information, such as reviewers' locations (Forman et al., 2008) and occupations (Shalev \& Morwitz, 2012). Those source cues have a significant influence on customer purchase decisions (Forman et al., 2008; Shalev \& Morwitz, 2012). However, more interest in recent years has been developed about the impact of reviewer images as social cues on customer behaviors, such as reviewer profile images (Karimi \& Wang, 2017). Image-based online reviews, as a new format of customer image, present actual buyers' images to potential customers. Potential customers usually could perceive the socioeconomic status of reviewers based on background details in image reviews. Although socioeconomic status is an important variable in social psychology research, the effect of socioeconomic status cues embedded in online reviews on customer behavior is still unexplored. This research tries to examine the socioeconomic effects of image-based online reviews on customer purchase intention.

\section{Self-Presentation Concern}

A considerable amount of research has investigated psychological mechanisms of social influence. The authors propose that social status effect is largely motivated by self-presentation concerns when customers read image reviews.

Goffman (1959), first introducing self-presentation, described a person managing self-presentation as an "actor". The person is likely to present himself favorably to others in everyday life similar to an actor on a stage (Goffman, 1959). The self-presentation motivations are to please others (the audience), to construct one's public self in a way that equates to his or her ideal self-image (Baumeister, 1982) and to express one's self-identity to others (Leary, 1995). To date, self-presentation motivation concern is widely addressed in social psychology research, especially in regards to personal webspace (Schau \& Gilly, 2003), personal homepage (Dominick, 1999; Jung et al., 2007; Doring, 2002), A-list blogs (Trammell \& Keshelashvili, 2005) and other social media platforms (Colliander et al., 2017; Fox \& Vendemia, 2016; Fullwood et al., 2016).

Self-presentation concern is often related to consumption. Moreover, customers' self-presentation concerns are distinctive between private and public consumption settings (Ratner \& Kahn, 2002; 
Sundar et al., 2017), similar to actors back-stage versus front-stage (Goffman, 1959; Goffman, 1978). Self-presentation concern is higher in a public consumption setting than in a private one (Sundar, 2017; White \& Dahl, 2006), and it has different influences on customer perceptions in private and public settings. Sundar (2017) showed that power perceptions mediate the influence of visual representation on service usage intentions, but this result happens only when service consumption occurs in public (Sundar, 2017). White and Dahl (2006) also found that dissociative reference groups are more influential for males when consumption takes place in public.

Customer consumption attempts to communicate symbolic meaning (Grubb et al., 1967) and to further present ideal social self-images to others (Sirgy, 1982). Customers use product consumption for self-definition (Solomon, 1983). When consumption occurs in public, customers are more concerned with their public appearances (Baumeister, 1982) and try to present a positive self-image to others (Wooten \& Reed, 2004). One's public self is constructed by selfpresentation (Baumeister1982). For example, clothing can be viewed as a possession to express self-presentation when clothing is consumed in public (Piacentini \& Mailer, 2004) and can be considered a "second skin" by which others see their owners (Belk, 1988). However, the selfpresentation concerns of customers would be reduced when clothing is consumed in a private setting (White \& Dahl, 2006). This is because customers do not need to present a positive image to others in private (White \&Dahl, 2006; Sundar et al., 2017).

\section{HYPOTHESIS DEVELOPMENT}

\section{Socioeconomic Status Background Embedded in Image Reviews}

Socioeconomic status is related to an individual's education and income, and it can be used to scale individual social class rank (Kraus et al., 2012; Adler et al., 2000). Perceived social class is the basis on which individuals rank themselves compared to others (Kraus et al., 2012). Individual socioeconomic status is rooted in different levels of material resources, such as consumed products (Krauset al., 2012). Accordingly, customers buy products not only for utilitarian benefits but also for satisfying their own social wants (Bhat \& Reddy, 1998). Some shared context information, such as pictures, can present observable symbols of wealth, education and occupation and thus can serve as signals of social class (Kraus et al., 2012). In this research, the authors suggest that the socioeconomic status of reviewers could be identified from image reviews.

Past work has shown that customers' attitudes and behaviors are directly influenced by attributes of information sources, regardless of the information included (Menon \& Blount, 2003; Forman et al., 2008). Customers primarily focus on possessions of the high-status group, and they diverge from the low status group (Berger \& Heath, 2007). Image-based online reviews often present socioeconomic status cues of product users to potential customers. When product users in image reviews are of low socioeconomic status, potential customers probably would decrease their purchase intention. In contrast, when product users in image reviews are of high socioeconomic status, potential customers probably would increase their purchase intention. Therefore, the authors predicted the following:

H1: A customer will have a greater intention to buy a product when the product is recommended by image reviews with higher SES reviewers than by those with lower SES.

\section{Product Consumption Setting}

In previous online review literature, the majority of scholars have demonstrated the moderation effect of product type (search vs. experience) on customer behaviors. Product consumption could occur in different consumption settings. Back to social status effect, the authors suggest that product consumption setting should be considered to further explore different influences of review sources on customer perceptions. 
Goffman (1978) has distinguished actors' different behaviors between frontstage and back-stage. Actors tightly obey norms and conventions to build their public image when they are front-stage, while they probably use substandard language and swear when they are backstage and out of the audience's view (Goffman, 1978). Similarly, customers have different behaviors in public and private settings. For example, customers would use brand choice to send a signal when a product is consumed in public (Wernerfelt, 1990). Customers would have more variety-seeking behaviors when their decisions are subject to public scrutiny (Ratner\& Kahn, 2002).

Moreover, social interaction would happen with products in a public setting. Male customers are less inclined to choose a product associated with female customers than a neutral product when the product is to be consumed in public, but this effect would be diminished when the product is consumed in a private setting (White \& Dahl, 2006). Extending this perspective, the authors introduce the product consumption setting as a key moderator of the influence of socioeconomic status on customers' attitudes. The authors suggest that the social status effect would be different when products are consumed in public or in private.

H2: The social status effect of image reviews is moderated by the product consumption setting. The social status effect will take place when the product is consumed in a public setting, but it does not occur when the product is consumed in a private setting.

\section{Customer Self-presentation Concern}

Different customers have different self-presentation concerns (White \& Dahl, 2006). The authors use self-presentation concerns to identify the mechanism of the social status effect based on image online reviews. Customers use a product as a symbol to express their identity to others (Schau \& Gilly, 2003). Therefore, self-presentation concerns would emerge for customers when they buy products consumed in public. Individual self-presentation demands impact their product choice (Solomon 1983). Customers with different self-presentation concerns have different attitudes on the same products with the same source cues (White \& Dahl, 2006; Sundar et al., 2017). In the public consumption setting, customers have greater intentions to buy a product that is recommended by high SES reviewers rather than by low SES reviewers when they are high in self-presentation concerns. Furthermore, customers who are low in self-presentation concerns will not be influenced by reviewer SES. The authors argue the following:

H3: In the public consumption setting, the social status effect of image reviews will be significantly highlighted when potential customers are in high self-presentation concerns but will not occur when potential customers are in low self-presentation concerns.

\section{RESEARCH METHOD}

In this study, an experiment is conducted to test these hypotheses. The authors conduct this research in three stages to develop a sound experimental procedure. First, this research identifies appropriate products, consumption settings and effective stimulus materials in the experiment. Second, a pilot study is conducted to check the manipulation: consumption settings and stimulus materials. Finally, the authors conduct the main experiment to test these hypotheses. The main experiment is a 2 (reviewer SES: high vs. low) $\times 2$ (product consumption setting: private vs. public) $\times 2$ (customer self-presentation concern: high vs. low) between-subjects design. Reviewer SES and product consumption setting is designed, and self-presentation concern is measured. 


\section{Selection of Products}

Clothing is selected as a product sample in the experiment. This is due to the symbolic meaning of clothing, the accessibility to customers (Banister \& Hogg, 2004) and their consumption settings. First, clothing consumption can convey consumers' tastes and values towards others in a public setting (Banister \& Hogg, 2004). Clothing is associated with customers' self-presentation (Piacentini \& Mailer, 2004). Moreover, the SES of clothing users has a significant impact on other potential customers' purchase intention (Shalev \& Morwitz, 2012). Second, clothing is used both for public and private occasions. This is appropriate in the experimental design. Third, most customers have experience with buying clothing online. Reports based on CNNIC (2017) showed that clothing was the largest-selling product online in China. Finally, as an experience product, clothing is appropriate for presentation based on image format reviews (Xu et al., 2015; Overmars \& Poels, 2015). Customers prefer to read image online reviews when they buy clothing (Liu \& Du, 2019). Furthermore, the authors choose a T-shirt as the product sample in the experiment based on relevant research (Shalev \& Morwitz, 2012).

\section{Consumption Setting Manipulation}

The authors manipulate consumption settings by using instructional statements that appear before T-shirt information introduction in the pilot study. The scenario in the experiment entails participants to purchase a product for themselves. In the public consumption setting, participants are asked to imagine that they are going to buy a T-shirt suited for a public occasion, such as having class or going out with friends. In the private consumption setting, participants are asked to imagine that they are going to buy a T-shirt suited only for home use. This imagination approach is adopted from past research (Mothersbaugh et al., 2012; Jin et al., 2014).

After reading the assumed setting and T-shirt introduction, participants are asked to respond to four questions for manipulation check (White\& Dahl, 2006). The items are measured on a sevenpoint Likert scale ranging from 1(extremely disagree) to 7 (extremely agree). The four items are shown in Table 1.

\section{Stimulus Material Manipulation}

The T-shirt information and its image reviews are both extracted from Taobao.com to make the experiment stimuli similar to real shopping websites. Taobao.com provides massive image reviews for us to select appropriate review samples in the experiment. The authors first select six image reviews sent by actual customers on Taobao.com. Each image review includes text content and one product image. The image reviews are about a fictional T-shirt apparel brand, which is modified by anonymizing any signs of the actual brand. The T-shirt brand is assumed "AB" to rule out famous brand effect. The selected image reviews not only provide T-shirt images posted by customers but also present SES cues of actual customers. Each image in these reviews has a clear product picture and an identifiable customer SES background. The text content in these reviews consists of approximately 60 words on average.

The authors manipulate reviewers' SES backgrounds (high vs. low) in the image reviews. Each condition includes three positive image reviews about the T-shirt. Moreover, three image reviews, as a manageable subset, is identified as high-SES background, and another three image reviews, as a manageable subset, is identified as low-SES background. To avoid a bias effect of different text content in two subsets, the authors select three text reviews as the text portion of each three image reviews for high SES and low SES, separately.

Participants answer four questions for each image review. The four items are about income, education, occupation and socioeconomic status (Shalev \& Morwitz, 2012; Kraus et al., 2012), as shown in Table 1. The scale ranges from 1 (extremely disagree) to 7 (extremely agree). The questions are the same as the items used to measure participants' recall on reviewers' SES in the main experiment. The results of the pilot study are used to further refine the list of image reviews, which becomes the final version used in the main study. 
Table 1. Measurement used in the study

\begin{tabular}{|c|c|}
\hline \multicolumn{2}{|c|}{ Purchase Intention Adapted from Gefen and Straub (2004) } \\
\hline Purchase intention 1 & I am very likely to buy the product recommended by this reviewer \\
\hline Purchase intention 2 & I intend to buy the product recommended by this reviewer \\
\hline \multicolumn{2}{|r|}{ Adapted from White and Dahl (2006); Scheier and Carver (1985) } \\
\hline Self-presentation concem 1 & I am concerned about my style of doing things \\
\hline Self-presentation concem 2 & I care a lot about how I present myself to others \\
\hline Self-presentation concerm 3 & I'm self-conscious about the way I look \\
\hline Self-presentation concern 4 & I usually worry about making a good impression \\
\hline Self-presentation concem 5 & Before Ileave my house, I check how I look \\
\hline Self-presentation concern 6 & I am concerned about what other people think of me \\
\hline Self-presentation concem 7 & $1 \mathrm{am}$ usually aware of my appearance \\
\hline \multicolumn{2}{|l|}{ Socioeconomic Status } \\
\hline Socioeconomic status 1 & The reviewer has a high socioeconomic status \\
\hline Socioeconomic status 2 & The reviewer has a prestigious occupation \\
\hline Socioeconomic status 3 & The reviewer has high income \\
\hline Socioeconomic status 4 & The reviewer was well educated \\
\hline \multicolumn{2}{|c|}{ Consumption Setting $\quad$ Adapted from White and Dahl (2006) } \\
\hline Consumption setting 1 & $\begin{array}{l}\text { Will you be dressing this T-shirt in the presence of others, such as having } \\
\text { class or going out with friends? }\end{array}$ \\
\hline Consumption setting 2 & $\begin{array}{l}\text { To what degree will your } T \text {-shirt will be dressed in public occasion of } \\
\text { having class or going out with friends? }\end{array}$ \\
\hline Consumption setting 3 & Will you be dressing this T-shirt only at home? \\
\hline Consumption setting 4 & $\begin{array}{l}\text { To what degree will your T-shirt will be dressed in private occasion, such } \\
\text { as at home? }\end{array}$ \\
\hline
\end{tabular}

\section{Experimental Procedures}

A total of 196 participants, undergraduate students from Xidian University, complete the main study of this experiment online. Participants get a bonus as a reward via "red envelope lucky draw" in We chat APP. Participants are randomly assigned to one of four conditions: 2 (reviewer SES: high vs. low) $\times 2$ (product consumption setting: private vs. public). Each treatment group includes approximately 49 participants.

The cover story explains that the research is focused on customers' attitudes towards online reviews. Consumption settings (public vs. private) are manipulated using imagination method at the beginning of the experiment. Next, participants are presented with a detailed T-shirt introduction, which includes a T-shirt image and text description provided by online vendors. Then, three image review stimuli (SES: high vs. low) follow. Participants are required to read the image reviews carefully. When they finish reading all of the information, participants respond to a few questions, including their purchase intention to this T-shirt and their own self-presentation concerns. Then, at the end of the experiment, participants are asked to recall the reviewers' SES that they have read and to subsequently answer questions to complete ratings of the reviewers' SES. The recall measure is a check to ensure that participants have paid enough attention to the product images in those reviews. If participants have received the reviewers' SES information embedded in the image reviews, participants should 
be able to correctly recall it. Finally, participants answer questions about their own background demographic information.

The dependent variable, purchase intention, is measured by two items from Gefen and Straub (2004). The second variable, self-presentation concern, is measured by seven items (White \& Dahl, 2006; Scheier \& Carver, 1985). Finally, reviewers' SES is measured by four items: income, education, occupation and socioeconomic status (Shalev \& Morwitz, 2012; Kraus et al., 2012). All responses above are measured on a seven-point Likert scale ranging from 1(extremely disagree) to 7 (extremely agree). Table 1 shows detailed survey items and supporting literature for the constructs used in this study.

This research also controls relevant variables, including review length, review valance, and image clarity. A longer review is perceived as more helpful (Yin et al., 2014). Thus, to avoid the effect of review length, the authors control review length and set it at an average of 60 words. In addition, all the reviews the authors selected are of a positive valance. In the pilot study, the authors control image clarity and further test whether the images in selected reviews have clear product pictures and identifiable SES cues of reviewers.

\section{RESULTS}

\section{Demographic Statistics}

Demographic measures indicate that the average age is 21 , and 60 percent of the participants are males. Participants have 6 years of online shopping experience on average. Moreover, they prefer to read online reviews prior to making a purchase decision. Table 2 demonstrates the descriptive statistics of the participants in this study.

Table 2. Descriptive statistics of participants in this study

\begin{tabular}{|c|c|c|}
\hline Dimension & Items & Percentage \\
\hline \multirow{2}{*}{ Gender } & Male & 60.2 \\
\cline { 2 - 3 } & Female & 39.8 \\
\hline \multirow{3}{*}{ Age } & $18-19$ & 16.3 \\
\cline { 2 - 3 } & $20-21$ & 65.3 \\
\cline { 2 - 3 } & $22-23$ & 18.4 \\
\hline \multirow{3}{*}{ Shopping experience } & Less than 2 years & 0 \\
\cline { 2 - 3 } & 3-4 years & 15.3 \\
\cline { 2 - 3 } & 5-6 years & 68.4 \\
\cline { 2 - 3 } & More than 7 years & 17.3 \\
\hline
\end{tabular}

\section{Manipulation Check}

The authors manipulate product consumption settings (public vs. private) and reviewers' SES background (high vs. low) in image-based online reviews. Thus, a pilot study is conducted to identify appropriate settings and effective stimuli for this experiment. An ANOVA is applied to check the manipulation.

First, the authors manipulate the product consumption setting (public vs. private). Forty-seven participants, undergraduate students, are required to read a consumption setting: public or private. Participants are randomly divided into two treatment groups and then are assigned into one of the consumption settings. Then, the participants respond to the measured items mentioned above. An ANOVA method reveals a significant difference of participant perception between the two settings. 
The results show that participants in assumed public settings perceive their consumption to be more public $\left(\mathrm{M}_{\text {private }}=3.04\right.$ versus $\left.\mathrm{M}_{\text {public }}=5.22, \mathrm{t}(22)=31.233, \mathrm{p}<0.001\right)$. In contrast, participants in private settings perceive their consumption to be more private $\left(\mathrm{M}_{\text {private }}=5.06\right.$ versus $\mathrm{M}_{\text {public }}=3.19$, $\mathrm{t}(23)=11.519, \mathrm{p}<0.001)$. Thus, the manipulation for consumption settings in this research is valid.

Second, the authors manipulate reviewers' SES (high vs. low) in image-based online reviews. Another seventy-seven participants, undergraduate students, complete reviewers' SES manipulation check. Participants are also divided into two treatment groups and randomly assigned into one condition. Then, for each treatment group, participants are presented the selected stimulus materials in random order, including three image reviews in each condition. The participants are required to answer the SES scales mentioned above. An ANOVA is also used to yield a significant main effect of SES background information $(\mathrm{F}(1,75)=975.472, \mathrm{p}<0.001)$. The pretest results confirm that the different background information evokes different perceptions on reviewers' $\operatorname{SES}\left(\mathrm{M}_{\text {low }}=2.331\right.$ versus $\left.\mathrm{M}_{\text {high }}=5.787, \mathrm{t}(75)=31.233, \mathrm{p}<0.001\right)$. Thus, the manipulation on reviewers' SES is effective.

\section{Tests of Hypotheses}

The authors first examine the reliability of the construct "purchase intention" in the study. Purchase intention is a first-order construct with reflective indicators. Cronbach's alphas for purchase intention are 0.845 , and those for self-presentation concern are 0.807 , demonstrating adequate internal reliability. In addition, the recall results in the experiment show that all participants are able to correctly recall the reviewers' background information embedded in the image reviews, thus suggesting that each participant has paid enough attention to the product images in those reviews.

Next, the authors use an ANOVA method to examine the main effect of a reviewer SES on customers' purchase intention. The results show that the main effect of a reviewer SES is significant on customers' purchase intention $(\mathrm{F}(1,192)=68.658, \mathrm{p}<0.001)$, indicating that participants have a higher purchase intention when they perceive the products recommended by high SES reviewers rather than by low SES reviewers $\left(M_{\text {high }}=4.63\right.$ versus $\left.M_{\text {low }}=3.61, t(194)=7.353, p<0.001\right)$. This result strongly supports H1, as illustrated in Figure 2.

Figure 2. Reviewers' social status effect on customers purchase intention

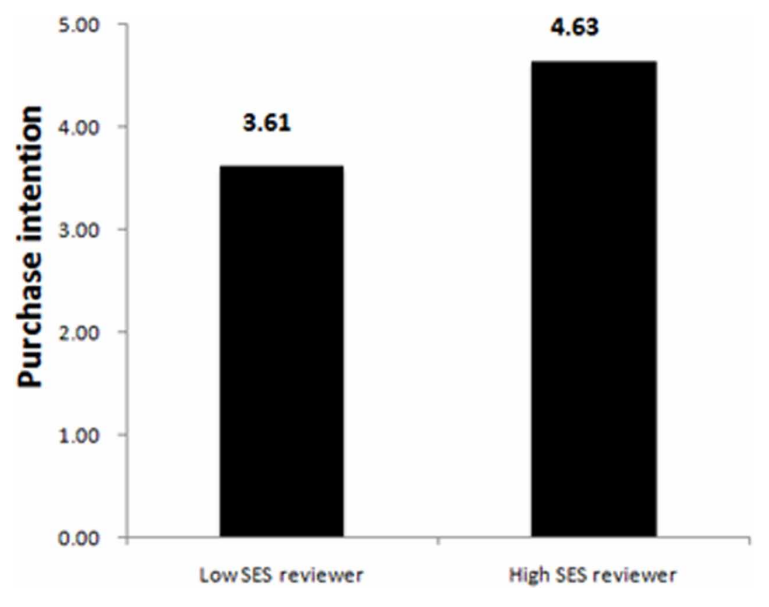

The second important aim in this research is to explore the different effects of reviewers' SES across different consumption settings. Unsurprisingly, the authors observe a significant interaction effect between consumption setting and reviewers' social status $(\mathrm{F}(1,192)=46.947, \mathrm{p}<0.001)$. The results show that participants have more purchase intention towards the products recommended 
by high SES reviewers than by low SES ones $\left(\mathrm{M}_{\text {high }}=4.78\right.$ versus $\mathrm{M}_{\text {low }}=2.97, \mathrm{t}(98)=9.667, \mathrm{p}$ $<0.001$ ) when the products would be consumed in public. In contrast, in the private consumption setting, participants' purchase intention have not been influenced by reviewers' $\mathrm{SES}\left(\mathrm{M}_{\text {high }}=4.46\right.$ versus $\left.\mathrm{M}_{\text {low }}=4.29, \mathrm{t}(94)=1.167, \mathrm{p}=0.245\right)$. The moderation effect of product consumption setting is illustrated in Figure 3.

Figure 3. Moderation effect of product consumption setting

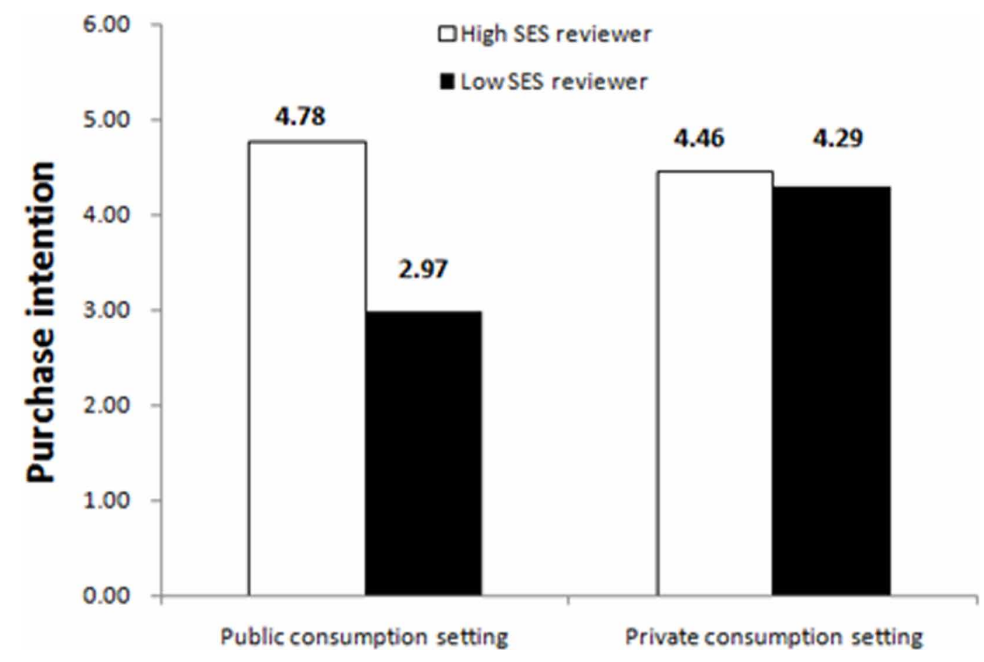

Next, more interestingly, the authors further delineate the underlying mechanism of the earlier findings by considering different self-presentation concerns between customers. The authors choose a median split of the self-presentation concern index based on relevant research (White \& Dahl, 2006). The results show that the interaction effect between public self-presentation concerns and reviewers' SES is significant $(\mathrm{F}(1,96)=144.463, \mathrm{p}<0.001)$. When the product is assumed to be consumed in a public setting, participants who are high in self-presentation concerns have heightened purchase intention towards products recommended by high-SES reviewers compared to low-SES reviewers $\left(\mathrm{M}_{\text {high }}=5.01\right.$ versus $\left.\mathrm{M}_{\text {low }}=1.50, \mathrm{t}(54)=17.162, \mathrm{p}<0.001\right)$. However, more interestingly, participants with low in self-presentation concerns have not been significantly influenced by reviewers' social status $\left(\mathrm{M}_{\text {high }}=3.72\right.$ versus $\left.\mathrm{M}_{\text {low }}=3.56, \mathrm{t}(42)=1.016, \mathrm{p}=0.316\right)$. The interaction effect of selfpresentation concern and SES is illustrated in Figure 4. All the results are shown in Table 3 and Table 4. The results of the hypothesis tests are shown in Table 5.

\section{DISCUSSION}

The current research examines a new social influence of online reviews on customers' purchase intention. This research focuses on reviewers' social background information reflected in imagebased online reviews. The social influence of online reviews has been a hot topic in past research. However, the authors' key argument is different from social influence based on text online reviews. To highlight the underlying mechanism of reviewers' social status effect, the authors explore to examine the different influence of consumption setting on customers' purchase intention, and then the authors deeply analyze the potential customers' psychological motives that generate social status effect from image online reviews on customers' purchase intention. 
Figure 4. Interaction effect of self-presentation concern and SES

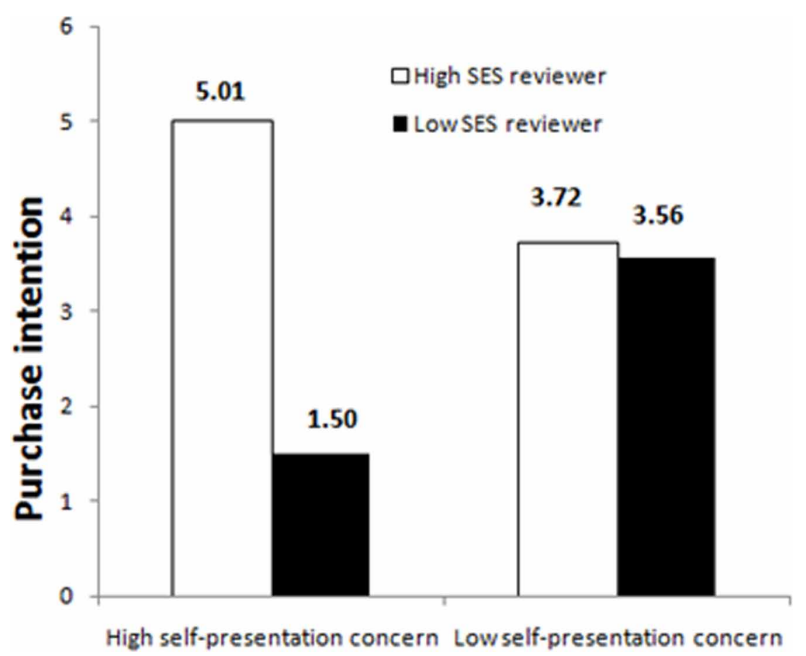

Table 3. Type III test of fixed effects of reviewers' SES and consumption setting

\begin{tabular}{|l|l|l|l|l|l|}
\hline & variable & Type III Sum of Squares & Df & F & sig \\
\hline Intercept & PI & 3332.330 & 1 & 4735.027 & 0.000 \\
\hline Reviewers' SES & PI & 48.319 & 1 & 68.658 & 0.000 \\
\hline $\begin{array}{l}\text { Reviewers' SES } \times \text { Product } \\
\text { consumption setting }\end{array}$ & PI & 33.040 & 1 & 46.947 & 0.000 \\
\hline
\end{tabular}

*Degree of freedom for errors was 192 PI: purchase intention

Table 4. Type III test of fixed effects of reviewers' SES and self-presentation concern

\begin{tabular}{|l|l|l|l|l|l|}
\hline & variable & Type III Sum of Squares & Df $^{\circ}$ & F & sig \\
\hline Intercept & PI & 809.631 & 1 & 2453.017 & 0.000 \\
\hline $\begin{array}{l}\text { Reviewers } \\
\text { self-presentation concem }\end{array}$ & PI & 47.681 & 1 & 144.463 & 0.000 \\
\hline
\end{tabular}

*Degree of freedom for errors was 96 PI: purchase intention

Table 5. Results of hypotheses tests

\begin{tabular}{|l|l|}
\hline $\begin{array}{l}\text { H1: A customer will have greater intentions to buy a product when the product is } \\
\text { recommended by image review with higher SES reviewer than by those with lower SES. }\end{array}$ & supported \\
\hline $\begin{array}{l}\text { H2: Social status effect of image reviews is moderated by the product consumption } \\
\text { setting. Social status effect will take place when the product is to be consumed in public } \\
\text { setting, but do not occur when the product is to be consumed in private setting. }\end{array}$ & supported \\
\hline $\begin{array}{l}\text { H3: In public consumption setting, social status effect of image reviews will be } \\
\text { significantly highlighted when potential customers are in high self-presentation concem, } \\
\text { but do not occur when potential customers are in low self-presentation concern. }\end{array}$ & supported \\
\hline
\end{tabular}


This research demonstrates that the social status effect occurs when customers read image-based online reviews to decide their purchase intentions in some conditions. Hypotheses 1 is supported. If a reviewer has low SES background information reflected in an image online review, potential customers would have less purchase intention to this product. In contrast, if the same target product is recommended by a reviewer with high SES reflected in an image online review, a potential customer would have more purchase intention to this product. However, this result diverges from prior findings on image-based online reviews. Liu and Du (2019) found that positive image-based online reviews provided more product understanding and then were perceived as more helpful than text-based online reviews. Furthermore, Xu et al. (2015) also found that highly positive perceived helpfulness of online reviews leads to greater purchase intention to the products. However, image reviews probably have negative influences on customers' purchase intention. This is because those previous researches did not consider the influence of review source cues. The authors' findings demonstrate whether positive image online reviews would lead to customers' greater purchase intention depending on reviewers' SES.

In addition, the conclusion is identical to the results of relevant research about interpersonal identification influence of online reviews (Shalev \& Morwitz, 2012). Shalev and Morwitz (2012) suggested that classic identification influences would take place when the focal trait of the product is ambiguous. However, Shalev and Morwitz (2012) did not further analyze the different influences of product consumption settings when customers read online reviews. The authors consider the product consumption setting to be a considerable factor in research about customer-product-customer relationship (Ratner\& Kahn, 2002).

The authors argue that the social status effect based on image reviews does not always take place in any product consumption setting. In other words, the social status effect depends on a moderator: product consumption setting. The authors discuss this argument systematically using product-social behavior relationships. The experimental results demonstrate that the social status effect is moderated by the product consumption setting when customers read image online reviews to make purchase decisions. Potential customers have heightened purchase intentions to the product recommended by actual customers with higher SES when potential customers buy this product for consumption in public. Conversely, potential customers have similar purchase intention to the product recommended by actual customers, regardless of high versus low status, when potential customers buy this product just for consumption in private. This result strongly supports hypotheses 2 in this research. Past research suggested that different pressures between public and private consumption lead to customers' different consumption decisions (Ratner\& Kahn, 2002; White \& Dahl, 2006). The authors' research further confirms this social status effect in the research field of online reviews.

Prior research was used to examine the moderation effect of different product attributes on textbased online reviews, for example, search products and experience products (Mudambi \& Schuff, 2010; Xu et al., 2015). However, the authors consider that product classification, divided into search and experience products, is not appropriate to deeply explore the different influences of reviewers' SES. The effect of reviewers' SES, which is viewed as a social cue, on image online reviews should be linked to an interpersonal effect when customers consume products. Most importantly, an interpersonal effect would occur only when products are consumed in public, but it would not occur in private consumption (Goffman, 1959; White \& Dahl, 2006). The experiment results also suggest that product consumption setting is an appropriate and important factor to be considered as a moderation variable in the research on source social status effect of image online reviews.

The results of hypotheses 3 demonstrate that the driving mechanism of social status effect could be explained by customers' self-presentation concerns. Participants with high self-presentation concerns would be significantly influenced by reviewers' SES when a product is consumed in the public. The finding in this research is consistent with the psychological process the authors suggested. Shalev and Morwitz (2012) first examined the link between the reviewer status effect and the social comparison mechanism and found that the exposure of a low-SES reviewer would worsen participants' self-affect. However, when considering product use occasions, self-presentation is a classic moderator of the social 
psychological process (White\& Dahl, 2006). In this research, the authors suggest that reviewers' social status effects should be interpreted by potential customers' self-presentation concerns, especially in the public consumption setting.

\section{THEORETICAL AND MANAGERIAL CONTRIBUTIONS}

Recently, a growing body of research focused on interpersonal identification of online reviews (Formanet al., 2008; Cheung et al., 2014; Davis \& Agrawal, 2018). The authors' study holds several important contributions to future research about social cues in online reviews. First, this research is among the first to examine the effects of reviewers' SES on image online reviews. Although past studies provided strong support for the effects of social cues in online reviews, the majority of researches only focused on descriptive information of reviewers' identities in text-based online reviews (Forman et al., 2008; Cheung et al., 2014; Davis \& Agrawal, 2018). While fruitful, few researches targeted reviewers' SES embedded in image-based online reviews. Reviewer SES issues are often overlooked. This would lead to an under estimation of the social status effect of reviewers and to an over estimation of the positive influence of some new review presentation formats, such as image-based (Liu \& Du, 2019) or video-based online reviews (Xu et al., 2015). The findings extend the knowledge base on the effects of source cues in online reviews from a new social perspective.

Second, the authors' findings contribute to enrich theories about product-social behavior relationships. Prior research about online reviews generally focused on the "customer-customer" interaction (Formanet al., 2008; Racherla et al., 2012). Consumed products are ignored in those researches. For instance, perceived background similarity (geographical location) between peer customers and potential customers has an influence on customers' trust in reviews (Racherla et al., 2012). On the other hand, most scholars are also used to considering different product types to explore the relationship of "product-customer" in research about online reviews. For example, Xu et al. (2015) suggested that online reviews generated different customer perceptions between search and experience products. This study extends the existing research to explore the whole "(peer) customer-product (consumed setting)-(potential) customer" relationship in this research field of online review. The authors introduce the product consumption setting as a moderate factor and demonstrate its moderation role in the social status effect of peer customers on potential customers' purchase intention. Thus, the authors consider that the findings contribute to enrich theories about product-social behavior relationships.

Finally, this research provides the first link between a reviewer SES and potential customers' self-presentation concerns. The authors' findings present deeper theoretical understanding of the mechanisms of social influence embedded in image online reviews.

This research also has managerial implications for online vendors, which could improve online marketing strategies for effectively managing image online reviews. For online vendors, the findings point to a double-sided influence of image-based online reviews. In practice, most online vendors only keep an eye on the positive effects of image-based online reviews (Liu \& Du, 2019). These online vendors make great efforts to stimulate actual buyers to post image reviews about products they sell. However, the products probably get a negative evaluation from those image review readers (potential customers), which is not what the online vendors want. Thus, the findings could help online vendors fully understand the double-sided effect of image reviews and then create appropriate strategies to decrease the amount of image reviews, which could reflect a reviewer's low SES. For instance, online vendors could stimulate actual buyers to post image reviews and advise them to protect their personal information or privacy, especially when SES background is clearly recognized as low in some image reviews. Thus, online vendors could achieve more large sales. On the other hand, if products are only consumed in private, such as a Wi-Fi adaptor, online vendors could ignore the effect of reviewers' social status. Online vendors do not have to encourage their buyers to post 
customers' images by marketing stimuli, such as cash rewards. The findings could help those online vendors reduce unnecessary marketing costs.

\section{LIMITATIONS AND FURTHER RESEARCH}

This research also has some limitations. First, the authors only select clothing as a product sample in the experiment. Clothing, viewed as an appearance-related product, may be more related to customers' self-presentation concerns compared to other products. This probably leads to a good test effect in the experiment. For instance, although some electronic products, such as a cell phone, are also consumed in public, the authors wonder whether the social status effect would occur or not. Liu and Du (2019) suggested that image-based online reviews had more of a significant influence on clothing than on cell phones. Thus, social status effect may not significantly occur when customers buy some products consumed in public, such as cell phones. Further research could deeply explore other factors influencing social status effect of image-based online reviews.

Second, other social theory probably could also explain social status effect of image-based online reviews. For example, using social identity theory (Tajfel \& Turner, 1986) as a framework, the authors could examine the conditions under which customers avoid products associated with a threatened aspect of their social identity. Future research could explore other related social theory to explain the effect of source identity disclosure on customers' perceptions when they read image-based online reviews. This would contribute to enrich theories about image online reviews.

Third, text content in image reviews is not considered in this research, such as perceived review quality (Zhao et al., 2017). Text content and source identity in image reviews would have an interactive effect on customers' perceptions (Racherla et al., 2012). Future research probably could consider this research direction.

Finally, all participants in this experiment are undergraduate students. The average age is approximately 21 years old. This could be another limitation of this research. Future research could expand participants' age ranges to test research conclusions further.

\section{CONCLUSION}

The authors use self-presentation concern to explain the driving mechanism of the social status effect when customers read image-based online reviews. The reviewers' social status effect is significant in the findings, especially when a product is consumed in a public setting. The results in this research suggest that positive image online reviews would probably not generate positive purchase intention to a product when the product is related to customers' self-presentation concerns. Online vendors should create appropriate strategies to manage image-based online reviews.

\section{ACKNOWLEDGMENT}

This research is supported by the National Natural Science Foundation of China through grant 71771184. It is also supported by Humanities and Social Science Talent Plan in Shaanxi through grant ER42015060002. 


\section{REFERENCES}

Adler, N. E., Epel, E. S., Castellazzo, G., \& Ickovics, J. R. (2000). Relationship of subjective and objective social status with psychological and physiological functioning: Preliminary data in healthy, white women. Health Psychology, 19(6), 586-592. doi:10.1037/0278-6133.19.6.586

Banerjee, S., Bhattacharyya, S., \& Bose, I. (2017). Whose online reviews to trust? Understanding reviewer trustworthiness and its impact on business. Decision Support Systems, 96, 17-26. doi:10.1016/j.dss.2017.01.006

Banister, E. N., \& Hogg, M. K. (2004). Negative symbolic consumption and consumers' drive for self-esteem. European Journal of Marketing, 38(7), 850-868. doi:10.1108/03090560410539285

Baumeister, R. F. (1982). A self-presentational view of social phenomena. Psychological Bulletin, 91(1), 3-26. doi:10.1037/0033-2909.91.1.3

Belk, R. W. (1988). Possessions and the extended self. The Journal of Consumer Research, 15(2), 139-168. doi:10.1086/209154

Belk, R. W., Bahn, K. D., \& Mayer, R. N. (1982). Developmental recognition of consumption symbolism. The Journal of Consumer Research, 9(1), 4-17. doi:10.1086/208892

Berger, J., \& Heath, C. (2007). Where consumers diverge from others: Identity signaling and product domains. The Journal of Consumer Research, 34(2), 121-134. doi:10.1086/519142

Bhat, S., \& Reddy, S. K. (1998). Symbolic and functional positioning of brands. Journal of Consumer Marketing, 15(1), 32-43. doi:10.1108/07363769810202664

Boster, F., Serota, K., Andrews, K., \& Carpenter, C. (2009). Influentials in America: A national study of the connector, persuader, and health maven scales. Proceedings of the annual meeting of the International Communication Association, Chicago, IL. Academic Press.

Chen, Y., Wang, Q., \& Xie, J. (2011). Online social interactions: A natural experiment on word of mouth versus observational learning. JMR, Journal of Marketing Research, 48(2), 238-254. doi:10.1509/jmkr.48.2.238

Cheung, C. M., Xiao, B. S., \& Liu, I. L. B. (2014). Do actions speak louder than voices? The signaling role of social information cues in influencing consumer purchase decisions. Decision Support Systems, 65(1), 50-58. doi:10.1016/j.dss.2014.05.002

Colliander, J., Marder, B., Falkman, L. L., Madestam, J., Modig, E., \& Sagfossen, S. (2017). The social media balancing act: Testing the use of a balanced self-presentation strategy for politicians using twitter. Computers in Human Behavior, 74, 277-285. doi:10.1016/j.chb.2017.04.042

Corey, L. G. (1971). People who claim to be opinion leaders: Identifying their characteristics by self-Report. Journal of Marketing, 35(4), 48-53. doi:10.1177/002224297103500409

Davis, J. M., \& Agrawal, D. (2018). Understanding the role of interpersonal identification in online review evaluation: An information processing perspective. International Journal of Information Management, 38(1), 140-149. doi:10.1016/j.ijinfomgt.2017.08.001

Dominick, J. R. (1999). Who do you think you are? personal home pages and self-presentation on the world wide web. Journalism \& Mass Communication Quarterly, 76(4), 646-658. doi:10.1177/107769909907600403

Döring, N. (2002). Personal home pages on the web: A review of research. Journal of Computer-Mediated Communication, 7(3), 1-29. doi:10.1111/j.1083-6101.2002.tb00152.x

Ekinci, Y., Sirakaya-Turk, E., \& Preciado, S. (2013). Symbolic consumption of tourism destination brands. Journal of Business Research, 66(6), 711-718. doi:10.1016/j.jbusres.2011.09.008

Forman, C., Ghose, A., \& Wiesenfeld, B. (2008). Examining the relationship between reviews and sales: The role of reviewer identity disclosure in Electronic Markets. Information Systems Research, 19(3), 291-313. doi:10.1287/isre.1080.0193

Fox, J., \& Vendemia, M. A. (2016). Selective self-presentation and social comparison through photographs on social networking sites. Cyberpsychology, Behavior, and Social Networking, 19(10), 593-600. doi:10.1089/ cyber.2016.0248 
Fullwood, C., James, B. M., \& Chen-Wilson, C. (2016). Self-concept clarity and online self-presentation in adolescents. Cyberpsychology, Behavior, and Social Networking, 19(12), 1-5. doi:10.1089/cyber.2015.0623

Gefen, D., \& Straub, D. W. (2004). Consumer trust in B2C e-Commerce and the importance of social presence: Experiments in e-Products and e-Services. Omega, 32(6), 407-424. doi:10.1016/j.omega.2004.01.006

Goffman, E. (1959). The presentation of self in everyday life. Doubleday, 21(3),655.

Goffman, E. (1978). The presentation of self in everyday life. Harmondsworth.

Grubb, E. L., \& Grathwohl, H. L. (1967). Consumer self-Concept, symbolism and market Behavior: A theoretical approach. Journal of Marketing, 31(4), 22-27. doi:10.1177/002224296703100405

Hirschman, E. C. (1981). Comprehending symbolic consumption: three theoretical issues in symbolic consumer behavior. Ann Arbor, MI: Association for Consumer Research.

Hogg, M. K., Banister, E. N., \& Stephenson, C. A. (2009). Mapping symbolic (anti-) consumption. Journal of Business Research, 62(2), 148-159. doi:10.1016/j.jbusres.2008.01.022

Holt, D. B. (1998). Does cultural capital structure American consumption? The Journal of Consumer Research, 25(1), 1-25. doi:10.1086/209523

Jin, L., Hu, B., \& He, Y. (2014). The recent versus the out-dated: An experimental examination of the timevariant effects of online consumer reviews. Journal of Retailing, 90(4), 552-566. doi:10.1016/j.jretai.2014.05.002

Jung, T., Youn, H., \& McClung, S. (2007). Motivations and self-presentation strategies on Korean-based "cyworld" weblog format personal homepages. Cyberpsychology \& Behavior, 10(1), 24-31. doi:10.1089/cpb.2006.9996

Karimi, S., \& Wang, F. (2017). Online review helpfulness: Impact of reviewer profile image. Decision Support Systems, 96, 39-48. doi:10.1016/j.dss.2017.02.001

Ketron, S. (2017). Investigating the effect of quality of grammar and mechanics (QGAM) in online reviews: The mediating role of reviewer credibility. Journal of Business Research, 81, 51-59. doi:10.1016/j.jbusres.2017.08.008

Khare, A., Labrecque, L. I., \& Asare, A. K. (2011). The assimilative and contrastive effects of word-of-mouth volume: An experimental examination of online consumer ratings. Journal of Retailing, 87(1), 111-126. doi:10.1016/j.jretai.2011.01.005

Kraus, M. W., Piff, P. K., Mendoza-Denton, R., Rheinschmidt, M. L., \& Keltner, D. (2012). Social class, solipsism, and contextualism: How the rich are different from the poor. Psychological Review, 119(3), 546-572. doi: $10.1037 / \mathrm{a} 0028756$

Leary, M. R. (1995). Self-presentation: Impression management and interpersonal behavior. Boulder, CO: Westview Press.

Levy, S. J. (1959). Symbols for sale. Harvard Business Review, 37, 117-124.

Liu, Y. M., \& Du, R. (2019). The effect of image-based online reviews on customers' perception across product type and gender. Journal of Global Information Management, 27(3), 139-158. doi:10.4018/JGIM.2019070108

López, M., \& Sicilia, M. (2014). Ewom as source of influence: The impact of participation in ewom and perceived source trustworthiness on decision making. Journal of Interactive Advertising, 14(2), 86-97. doi:10 $.1080 / 15252019.2014 .944288$

Menon, T., \& Blount, S. (2003). The messenger bias: a relational model of knowledge valuation. Research in Organizational Behavior, 25(3), 137-186. doi:25004-810.1016/s0191-3085(03)

Mothersbaugh, D. L., Foxx, W. K. II, Beatty, S. E., \& Wang, S. (2012). Disclosure antecedents in an online service context: The role of sensitivity of information. Journal of Service Research, 15(1), 76-98. doi:10.1177/1094670511424924

Mudambi, S. M., \& Schuff, D. (2010). What makes a helpful online review? A study of customer reviews on amazon.com. Management Information Systems Quarterly, 34(1), 185-200. doi:10.2307/20721420 
Overmars, S., \& Poels, K. (2015). Online product experiences: The effect of simulating stroking gestures on product understanding and the critical role of user control. Computers in Human Behavior, 51, $272-284$. doi:10.1016/j.chb.2015.04.033

Pan, Y., \& Zhang, J. Q. (2011). Born Unequal: A study of the helpfulness of user-generated product reviews. Journal of Retailing, 87(4), 598-612. doi:10.1016/j.jretai.2011.05.002

Park, C. W., Jaworski, B. J., \& MacInnis, D. J. (1986). Strategic brand concept image management. Journal of Marketing, 50(4), 135-145. doi:10.1177/002224298605000401

Piacentini, M., \& Mailer, G. (2004). Symbolic consumption in teenagers clothing choices. Journal of Consumer Behaviour, 3(3), 251-262. doi:10.1002/cb.138

Prónay, S., \& Hetesi, E. (2016). Symbolic consumption in the case of brand communities. Society and Economy, 38, 87-102. doi:10.1556/204.2016.38.1.6

Racherla, P., Mandviwalla, M., \& Connolly, D. J. (2012). Factors affecting consumers trust in online product reviews. Journal of Consumer Behaviour, 11(2), 94-104. doi:10.1002/cb.385

Ratner, R. K., \& Kahn, B. E. (2002). The impact of private versus public consumption on variety-seeking behavior. The Journal of Consumer Research, 29(2), 246-257. doi:10.1086/341574

Schau, H. J., \& Gilly, M. C. (2003). We are what we post? self-presentation in personal web space. The Journal of Consumer Research, 30(3), 385-404. doi:10.1086/378616

Scheier, M. F., \& Carver, C. S. (1985). The self-consciousness scale: A revised version for use with general populations. Journal of Applied Social Psychology, 15(8), 687-699. doi:10.1111/j.1559-1816.1985.tb02268.x

Schenk, C., \& Holman, R. (1979). A sociological approach to brand choice: The concept of situational self-image. Advances in Consumer Research. Association for Consumer Research, 7(1), 610-614.

Sengupta, J., Dahl, D. W., \& Gorn, G. J. (2002). Misrepresentation in the consumer context. Journal of Consumer Psychology, 12(2), 69-79. doi:10.1207/S15327663JCP1202_01

Shalev, E., \& Morwitz, V. G. (2012). Influence via comparison-driven self-evaluation and restoration: The case of the low-status influencer. The Journal of Consumer Research, 38(5), 964-980. doi:10.1086/661551

Sirgy, M. J. (1982). Self-concept in consumer behavior: A critical review. The Journal of Consumer Research, 9(4), 287-300. doi:10.1086/208924

Solomon, M. R. (1983). The role of products as social stimuli: A symbolic interactionism perspective. The Journal of Consumer Research, 10(3), 319-329. doi:10.1086/208971

Solomon, M. R., \& Englis, B. G. (1996). I am not, therefore I am: the role of anti-consumption in the process of self-definition. Proceedings of the Special Session at the Association for Consumer Research conference, Tucson, AZ. Academic Press.

Srinivasan, S. S., Anderson, R., \& Ponnavolu, K. (2002). Customer loyalty in e-commerce: An exploration of its antecedents and consequences. Journal of Retailing, 78(1), 41-50. doi:10.1016/S0022-4359(01)00065-3

Strodtbeck, F. L., James, R. M., \& Hawkins, C. (1957). Social status in jury deliberations. American Sociological Review, 22(6), 713-719. doi:10.2307/2089202

Sundar, A., Dinsmore, J. B., Paik, S. W., \& Kardes, F. R. (2017). Metaphorical communication, self-presentation, and consumer inference in service encounters. Journal of Business Research, 72, 136-146. doi:10.1016/j. jbusres.2016.08.029

Tajfel, H., \& Turner, J. C. (1986). The social identity theory of intergroup behavior. Psychology of Intergroup Relations, 13(3), 7-24.

Trammell, K. D., \& Keshelashvili, A. (2005). Examining the new influencers: A self-presentation study of a-list blogs. Journalism \& Mass Communication Quarterly, 82(4), 343-347. doi:10.1177/107769900508200413

Veblen, T. (1994). The theory of the leisure class. New York: Macmillan. 
Wernerfelt, B. (1990). Advertising content when brand choice is a signal. The Journal of Business, 63(1), 91-98. doi:10.1086/296485

White, K., \& Dahl, D. W. (2006). To be or not be? the influence of dissociative reference groups on consumer preferences. Journal of Consumer Psychology, 16(4), 404-414. doi:27663jcp1604_1110.1207/s153

Wooten, D. B., \& Reed, A. II. (2004). Playing it safe: Susceptibility to normative influence and protective selfpresentation. The Journal of Consumer Research, 31(3), 551-556. doi:10.1086/425089

Xu, P., Chen, L., \& Santhanam, R. (2015). Will video be the next generation of e-commerce product reviews? Presentation format and the role of product type. Decision Support Systems, 73(3), 85-96. doi:10.1016/j. dss.2015.03.001

Yin, D., Bond, S. D., \& Zhang, H. (2014). Anxious or angry? effects of discrete emotions on the perceived helpfulness of online reviews. MIS Quarterly, 38(2), 539-560. doi:/2014/38.2.1010.25300/misq

Zhang, K. Z., Zhao, S. J., Cheung, C. M., \& Lee, M. K. (2014). Examining the influence of online reviews on consumers decision-making: A heuristic-systematic model. Decision Support Systems, 67, 78-89. doi:10.1016/j. dss.2014.08.005

Zhao, K., Stylianou, A. C., \& Zheng, Y. (2017). Sources and impacts of social influence from online anonymous user reviews. Information \& Management, 55(1), 16-30. doi:.2017.03.00610.1016/j.im

Yuming Liu is a lecture of business administration at Xidian University in China. Her research interests include consumer behaviors, online reviews, and information management. Her prior research has been published in some national or international journals, such as journal of global information management.

Rong Du is a chair professor of management at the School of Economics and Management, Xidian University, China. She was a visiting professor in the Department of Computer Information Systems, Georgia State University, US, the Department of Information Systems and Computing, Brunel University, UK, and the MIS Department of Quinn School of Business, University College Dublin, Ireland. Her research interests include information systems and knowledge management. She has published papers in journals such as Journal of Global Information Management, Journal of Strategic Information Systems, Expert Systems with Applications, European Journal of Operational Research, Information Systems Management, Chinese Management Studies, etc. She is a scholar selected into the New Century's Excellent Talent Supporting Program by the Ministry of Education in China. 